\title{
Improvement of Water Balance Model Based on Wireless Water Sensor
}

\author{
Li Shijuan ${ }^{1, a}$ and Zhu Yeping ${ }^{2, b}$ \\ ${ }^{1}$ Key Laboratory of Agri-information Service Technology, Ministry of Agriculture; Agricultural \\ Information Institute, Chinese Academy of Agricultural Sciences, Beijing, 100081 China \\ alishijuan@caas.cn, 'bhuyeping@caas.cn
}

Keywords: Water balance model, wireless sensor, improvement, wireless sensing networks

\begin{abstract}
Water plays an important role in the crop growth and development. So simulation of water balance is a significant part of crop growth simulation all the time. But it needs many parameters. And the simulation accuracy depends on the values of parameters. With the rapid development of water sensor and wireless sensing network, more and more wireless sensing data are used to guide field irrigation and agricultural production. The author tried to apply real-time soil water content collected with wireless water sensor to improve the traditional water balance model in order to reduce the calculation error and statistical error. The results will help to increase the simulation and forecast performance of crop growth model.
\end{abstract}

\section{Introduction}

Water is the important media to connect soil, crop and atmospheric system. Water balanced budget is one of the outstanding prerequisites to ensure the high yield [1]. As an important factor, water plays decisive role in the plant. Water involves in various physiological processes, so the change of soil water content affects closely plant growth and development. Water is the main limiting factor in arid and semi-arid areas. The variation of soil water dynamic needs to be understood in order to determine the optimal water management. The rapid and accurate measurement of soil water content has significant meaning for exploring the soil water budget in the different growing stages to provide appropriate irrigation schedule and drainage measures.

\section{Research on Simulation of Water Balance}

Unsaturated soil water flow decides the water distribution in different depth and time in the soil profile, then affects the water budget directly which has a significant influence on crop development [2]. Therefore, research on simulation of water balance is one of important research areas of related disciplines all the time.

There are many dynamic factors to influence the soil water content such as meteorological phenomena, soil characteristics and vegetation status etc. The influences of these factors to soil water and the feedbacks of soil water to these factors construct the soil water dynamic among soil, plant and atmosphere (SPAC) with complicated mechanization [3]. A series of hypotheses will be set up: the soil property is similar and uniform; there is no air resistance to water flow in soil; the impact pf temperature is negligible; the relationships between soil diffusivity, soil hydraulic conductivity and soil water content are uniform functions; the influence of chemical action on soil water do not be considered. Chen $\mathrm{J}$ et al constructed soil water simulation model with 10 days as a forecast interval by using statistical methods. The critical value of rainfall was introduced to improve the model simulation ability. But the accuracy of simulation results depended on whether the determining method of critical value was correct or not [4].

In general, there are two main means to study field water cycle. One is the hydrodynamics-based filed water movement model. The other is the water balance model for certain region or field. The former regards the water with different status as a unified system to construct model by hydrodynamics method. System characteristics are confirmed by all kinds of variables. The latter 
calculates the water input and output within the crop root area in certain period of time. Although soil water movement model can express the dynamics of soil water in the smaller time and spatial scales, it involves in more parameters and has not been applied popularly. Compared with hydrodynamics-based filed water movement model, equilibrium assignment model of soil water is simple and effective [5]. In the general case water equilibrium assignment model can reach certain simulation accuracy [6].

The variation of soil pondage in root layer can be expressed with following equation.

$\mathrm{W}=\mathrm{R}+\mathrm{I}-\mathrm{E}-\mathrm{T}-\mathrm{D}$

Among them, $\mathrm{R}$ is rainfall; $\mathrm{I}$ is the amount of irrigation; $\mathrm{E}$ is evaporation; $\mathrm{T}$ is transpiration; $\mathrm{D}$ is the amount of drainage leaked from root layer. $\mathrm{E}$ is a main expenditure. Its determination affects the calculation accuracy of soil water and the design of irrigation management system as well as the simulation of crop yield and calculation accuracy. Crop evaporation is computed with potential transpiration, which is based on Penman-Monteith equation.

Water balance model is an important part of crop simulation growth model all the time [7]. crop simulation model has been studied for decades, and the relevant technologies are mature at present. Woods constructed a universal water consuming model [8]. Bhadra et al set up a water balance model for rice, which simulated the stages of water storage, saturation and exhaustion. The parameter included the data of soil, crop and weather [9]. Gomez et al developed a water balance model which described the key water process in rainfed olive orchard and simulated the effects of different managements on water balance [10]. Li X et al studied the movement rules and regulation of soil water [11]. He thought it was necessary to consider the water movement rules from the time scale of 1 year or more. Theoretical solution and emprical formula under simple boundary condition are not enough for studying the soil water movement rules in field. The facts are very complicated. So it is necessary to set up mechanism model to simulate annual water dynamic and adopt effective numerical methods to analyze.

Water balance model with more mechanization simulates the soil movement in profile, plant transpiration, evaporation, infiltration, runoff and drainage by computing water circulation, potential evaporation, root growth and water uptake in order to determine the water content in different soil layer, water demand of certain crop and the water loss [12]. The model complexity decides the input of plenty of parameters. It is difficult to determine the parameters' values for the non-experts. Mechanism model based on processes takes soil, plant and environment as a system. The changes of each component such as surface precipitation, evaporation, runoff and vertical movement of soil water are described to simulate soil content. But the accuracy of simulation results is related with model structure, numerical values of parameters and inputting data.

Liu Z et al used the mechanistic ecosystem model BEPS (boreal ecosystem productivity simulator) to simulate SWC and evapotranspire of farm lands in areas with a monsoon climate [13]. Simulated SWC was compared with measurements in the growing seasons of winter wheat during 2000 to 2004 at Xuzhou agrometeorological station, Jiangsu province. The results showed that BEPS model was in general able to capture the seasonal and inter-annual variations of SWC.

Water is a parameter which changes at all times. Water balance model is a basic sub-model of crop growth model. If the correlation between actual data and water balance model are found to reduce the computing and statistical errors, the simulation and forecast performances will be improved qualitatively [14].

\section{Soil Water Sensors and the Application in Agriculture}

Monitoring instruments for soil water are divided into the following types according to the measure principles. 1) Time domain reflection type instrument (TDR); 2) Time domain transmission type instrument (TDT); 3) Frequency domain reflection type instrument (FDR); 4) Neutron probe type instrument (NP); 5) Negative pressure instrument (TM); 6) Resistance instrument. 
The different sensors with different principles have their own advantages and disadvantages. Although NP can monitor the water dynamic of certain soil layer for a long time, the accuracy is lower than that of the other methods. TDR can measure soil water content with high accuracy quickly in real time, but the cost is too high to spread. So TDR method can't be used to rural soil water content monitoring and automatic water-saving control system.

Wireless Sensor Technologies (WST) is entering a new phase. WSN can operate in a wide range of environments and provide advantages in cost, size, power, flexibility and distributed intelligence, compared to wired ones. WST have a big potential for represent the inherent soil variability present in fields with more accuracy than the current systems available. The use of sensors to monitor the soil water status enables irrigation scheduling to be adapted to the particular requirements of individual crops and fields [15].Thus, the benefit for the producers is a better decision support system that allows to maximize their productivity while saving water [16].

Many researchers have worked with soil water monitoring, collection and analysis based on WST. Liu $\mathrm{H}$ et al established soil temperature and humidity monitoring system [17]. Gao F et al developed crop water situation measurement system based on wireless sensing network (WSN-CWSM) [18]. Kim et al. develop an in-field WSN for implementing site specific irrigation control in a linear move irrigation system [19].Qian et al. designed a new groundwater-monitoring instrument based on WSN. The new instrument monitors groundwater table and temperature through a sensor. An embedded singlechip processes the monitoring data and a GSM data module transfers the data wirelessly [20].

\section{Integration of Water Balance Model and Wireless Sensing Data}

General water balance model adopts the following simulation method. A series of initial parameters are set up according to water balance principle. Then the SCS curve number method, lamination method, equation of Priestly-Taylor or Penman etc. are used to simulate the soil water content in profile in order to calculate the plant water uptake, transpiration, evaporation and drainage etc.

Potential available water in each layer can be acquired easily if the real-time soil water contents from wireless sensors are integrated into crop growth model. Assumptions and deductions will be reduced. Then the systematic error decreases and the simulation accuracy increases. But this method can't distinguish the processes of evaporation, drainage and transpiration etc., which are important to crop growth simulation and can affect the other parts such as plant growth, fertilizer uptake. Therefore how to inverse daily evaporation, drainage and transpiration etc. that will be coupled with crop growth model by using inversion simulation technology and optimization theory is a key problem need to be resolved. The following figure is the inversion flow chart. 


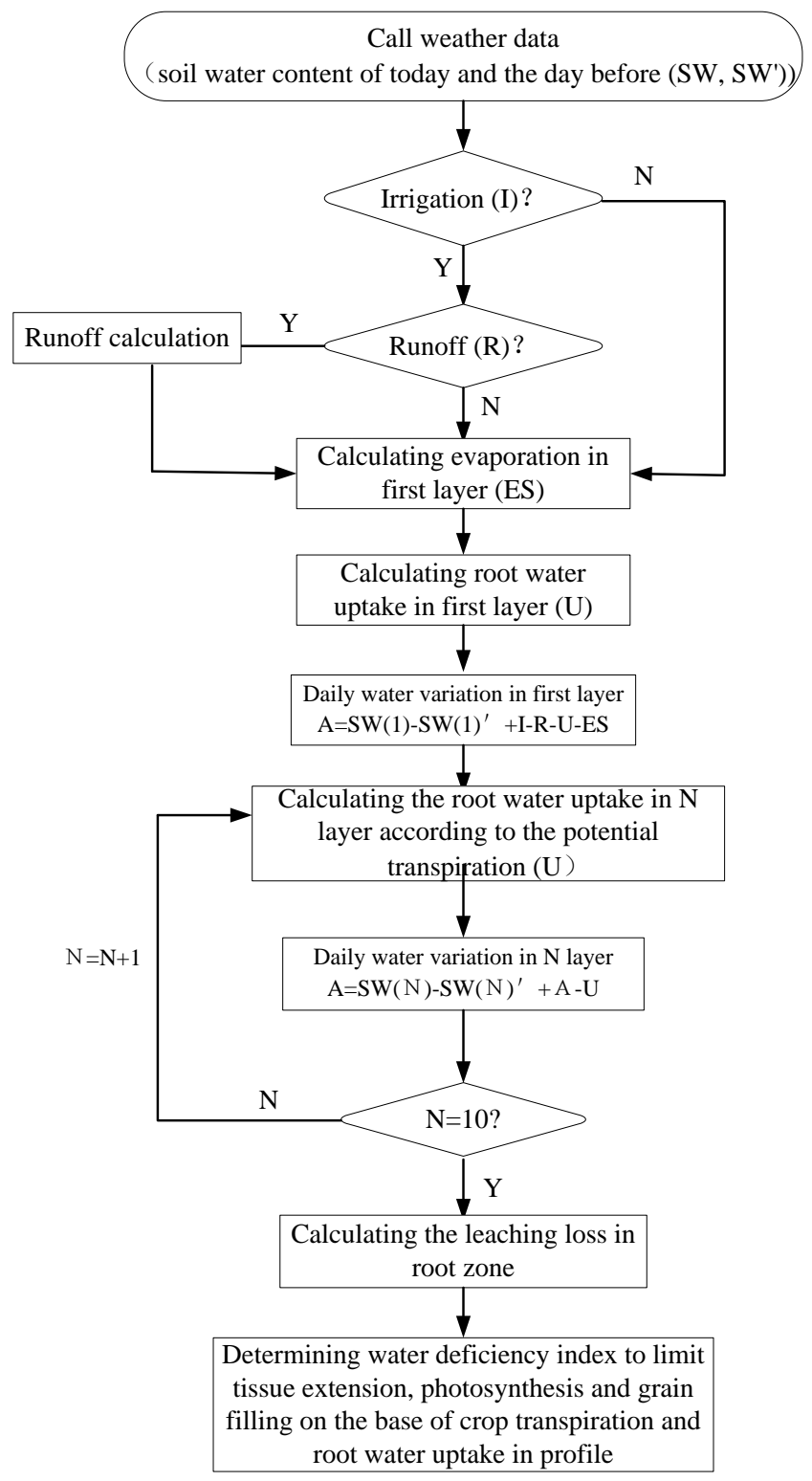

Fig.: Daily evaporation, drainage and transpiration inversion flow chart based on real-time soil water content

\section{Summary}

Traditional water balance model calculates water deficiency index by a series of hypothesizes and derivation on the basis of a lot of initial parameters. This study tries to make use of the real-time soil water content based on wireless sensors. The water evaporation, water uptake in each soil layer, runoff etc. will be recalculated. Water leaching loss from root layer and the water deficiency index will be inverted ultimately. The latter will go on participate the other processes of crop growth and development. This study hopes to construct the relationship between real-time water soil content and water balance model to reduce the medium processes and decrease the errors in order to enhance the simulating ability for water budget. The design idea is beneficial to the other study about the water balance.

\section{Acknowledgements}

This research is supported by State High-tech Research and Development Project of China (Grant No. 2013AA102305), Scientific and Technical Innovation Project of CAAS "Innovation team for intelligent control and virtual technology of agricultural systems” (CAAS-ASTIP-2015-AII-03) and 
Special Fund of Basic Scientific Research and Operation Foundation for Commonweal Scientific Research Institutes (2015-J-02).

\section{References}

[1] S. Banedjschafie, S. Bastani and P. Widmoser et al: Improvement of Water Use Efficiency and $\mathrm{N}$-fertilizer Efficiency by Subsoil Irrigation of Winter Wheat. European Journal of Agronomy Vol. 28 (2008), p. 1-7.

[2] Z. D. Lei, S. X. Yang and C. X. Xie: Soil Water Dynamics (Tsinghua University Press, Beijing 1988).

[3] Y. Yang, A. Guo and S. An et al: Research on Plant Root Water Uptake Models in Soil Plant Atmosphere Continuum. Chinese Academy of Meteorological Sciences Vol. 32(5) (2004), p. 316-321.

[4] J. H. Chen, T. M. Yang and X. Q. Ma et al: A Dynamic Simulation on Soil Moisture in North of Yangtze River in Anhui Province. Chinese Journal of Agrometeorology Vol. 28(3) (2007) p. 289 $-291$.

[5] Z. Chen and V. Michel: Research on Soil Water Balance in Fengqiu Region, III. Water Flux Pass Through the Boundary of Root Zone. Acta Pedologica Sinica Vol. 28(1) (1991), p. 66-72.

[6] Y. Gong, C. Li and Z. Li: Comparison of Three Methods for Measuring Soil Moisture in the Field. Journal of China Agricultural University Vol. 2( 3 ) (1997), p. 53-58.

[7] J. G. Kroes, J. C. Van Dam and P. Groenendijk et al: SWAP Version 3.2: Theory Description and User Manual. Alterra Report 1649, Wageningen: Alterra (2008).

[8] H. A. Woods and J. N. Smith: Universal Model for Water Costs of Gas Exchange by Animals and Plants. Proceedings of the National Academy of Sciences of the United States of America Vol. 107(18) (2010), p. 8469-8474.

[9] A. Bhadra, A. Bandyopadhyay and R. Singh: Development of a User Friendly Water Balance Model for Paddy. Paddy and Water Environment Vol. 11(1-4) (2013), p. 331-341.

[10] J. A. Gomez, U. Abazi and I. J. Lorite et al: WABOL: A Conceptual Water Balance Model for Analyzing Rainfall Water Use in Olive Orchards under Different Soil and Cover Crop Management Strategies. Computers and Electronics in Agriculture Vol. 91(2013), p. 35-48.

[11] X. C. LI and S. H. Shang: Simulation of Water Cycling in Wheat-maize Field in North China. Journal of Irrigation and Drainage Vol. 22(5) (2003), p. 10-16.

[12] D. Yang T. Zhang and K. Zhang, et al: An Easily Implemented Agro-hydrological Procedure with Dynamic Root Simulation for Water Transfer in the Crop-soil System: Validation and Application. Journal of Hydrology Vol. 370(2009), p. 177-190.

[13] Z. Liu, Y. L. Zhou and W. M Ju et al: Simulation of Soil Water Content in Farm Lands with the BEPS Ecological Model. Transactions of the Chinese Society of Agricultural Engineering Vol. 27(3) (2011), p. 67-72.

[14]D. J. Greenwood, K. Zhang and H. W. Hilton et al: Opportunities for Improving Irrigation Efficiency with Quantitative Models, Soil Water Sensors and Wireless Technology. Journal of Agricultural Science, Vol. 148 (2010), p. 1-16.

[15] R.B. Thompson, M. Gallardo and T. Agüera et al: Fernández Evaluation of the Watermark Sensor for Use with Drip Irrigated Vegetable Crops. Irrigation Science Vol. 24 (2006), p. 185-202. 
[16] Luis Ruiz-Garcia, Loredana Lunadei and Pilar Barreiro et al: A Review of Wireless Sensor Technologies and Applications in Agriculture and Food Industry: State of the Art and Current Trends. Sensors Vol. 9(2009), p. 4728-4750.

[17] H. Liu and M. H. Wang: Development of Farmland Soil Moisture and Temperature Monitoring System Based on Wireless Sensor Network. Journal of Jilin University (Engineering and Technology Edition) Vol. 38(3) (2008), p. 604-608.

[18]F. Gao, L. Yu and W. A. Zhang et al: Research and Design of Crop Water Status Monitoring System Based on Wireless Sensor Networks. Transactions of the Chinese Society of Agricultural Engineering Vol. 25(2) (2009), p. 107-112.

[19] Y. Kim, R.G. Evans and W.M. Iversen: Remote Sensing and Control of an Irrigation System Using a Distributed Wireless Sensor Network. IEEE Trans. Instrum. Meas. Vol. 57(2008), p. 1379-1387.

[20] D. Qian, Y. Shi and K. Zhang, in: Study of Wireless-sensor-based Groundwater Monitoring Instrument, edtied by St. Joseph, MI, Watershed Management to Meet Water Quality Standards and TMDLS (Total Maximum Daily Load), ASABE, San Antonio, TX,. USA. American Society of Agricultural and Biological Engineers (2007). 